\title{
The mecanoterapia, therapeutic alternative for the veined inadequacy
}

\begin{abstract}
Thinks about that Cuba traffics quickly not toward the populational aging with prevalence of the chronic illnesses transmissible (ECNT) and the lesions of there the urgency to begin programs and interventions of primary and secondary prevention, with low costs and an appropriate level of benefits It didn't exist in our institution a plan of exercises that was adjusted to the patient payee's of inadequacy veined chronicle requirements posturales (IVC) being the veined rest one of the pillars in the treatment of the veined inadequacy. The mecanoterapia is one of the oldest therapeutic modalities. In the 1943 approximately Guthrie Smith already used it in the treatment of motive sequels, his application arrives until our days. The Cage of Roche is part of the equipment of our rehabilitation rooms it is an enclosure in cage form whose principle physique is to eliminate the force of graveness during the physical exercise, for it the cage of Roche can be the I implement appropriate for the necessary invigoration of the muscular bomb of the calf in the patient payees of (IVC) and other pathologies where the veined rest is the posture of therapeutic election.
\end{abstract}

Keywords: approximately, prevalence, therapeutic election, mecanoterapia, eliminate
Volume 12 Issue $3-2019$

\author{
Anicia Hernández Soublett \\ National Institute of Angiology and Vascular surgery, Cuba
}

Correspondence: Anicia Hernández Soublett, National Institute of Angiology and Vascular surgery, Cuba,

Email aniciahdez@infomed.sld.cu

Received: April 27, 2019 | Published: June 26, 2019
Abbreviations: ECNT, chronic illnesses transmissible; IVC, inadequacy veined chronicle

\section{Introduction}

The non transferable illnesses ENT represent $63 \%$ of the total number of deaths. Mainly the cardiovascular illnesses, the cancer, the chronic breathing illnesses and the diabetes are, responsible for $63 \%$ of the deaths that take place in the world (36 million 57 million global deaths). $80 \%$ of the ENT is given in the countries of low revenues and means. More than 9 millions of the attributable deaths to the ENT take place in people smaller than 60 years. In world terms, the ENT affects men equally and women are in great measure prevenibles by means of effective interventions that approach the factors of risk, the main factors of risk they are the tabaquismo, the noxious use of the alcohol, the bad feeding and the lack of physical activity, the non alone ENT constitutes a sanitary problem but also a challenge as regards development. They subject many people to the poverty, or they maintain them sunk in her, due to the catastrophic medical expense that you/they involve. In 2008, 1,500 million adults (of 20 and more years) they had overweight. In the 2010 around 43 million children smaller than five years had overweight. ${ }^{1}$

The International Union of Flebología defines the inadequacy veined chronicle (IVC) as The changes taken place in the inferior extremities as a result of the lingering veined hypertension. ${ }^{2,3}$ are the price of the bipedestación and the flaw in the physiologic mechanisms that help to the veined return from the extremities to the heart, the muscular contracture of the calf in the march, the system veined valvular and the negative pressure of the thorax during the inspiration, among otros. ${ }^{4}$

Inside the signs that characterize this illness they are the edema, the lipodermatosclerosis, the hyper pigmentation, the eczema, the erysipelas and the veined ulcers, I square resultant from the estasis secondary capillary venules to the progressive increase and in permanent way of the veined pressure of those. Inferior members. The most common presentation forms are the varies and the veined ulcers, and this last one is considered the most serious manifestation in the IVC and the most difficult in tratar. ${ }^{5}$ According to obtained data of the study RELIEF ${ }^{5}$ in the western world, between the 10 and the mature population's $15 \%$ they present varies, while in the case of the veined ulcers he/she is considered that the prevalence is between the 1 and $2 \%$ of the población. ${ }^{6}$

A group of conditions has been identified that they increase the probability of appearance of the IVC. These factors of risk usually act on the mechanisms physiologic present adaptations in the vascular system, like they are; the mechanisms of distension contraction and of vascular remodeling that you/they allow to face the changes in the volume with their action and in the pressure of the blood. The first epidemic studies in Cuba on the IVC were carried out in the decade of 70 in last century and so far they had not been carried out studies of bring up to date. In investigation practiced in the municipality Hill of the county of Havana he/she was proven that it is not exempt of this situation, for what is objective of this study, to estimate the incidence and the prevalence of the IVC in this municipality, and to identify the clinical manifestations and the symptoms that made the patients to go to the consultations of angiology. ${ }^{8}$

$\mathrm{He} / \mathrm{she}$ was carried out a traverse study, with a sampling for conglomerates to determine which the number of necessary areas of health was. They were studied, selected at random, two policlinics of the four of the municipality Hill. All the patients payees of IVC that went to the consultations of Angiology of this polyclinics were included supposedly and those that attended the external consultations of the service of Flebolinfologia, of the National Institute of Angiology and Vascular Surgery during the period of one year. ${ }^{8} 479$ residents interviewed all they went patient that went to the consultations, they were carried out an interrogation, a physical, filled exam a questionnaire and being diagnosed or IVC don't unite. They were explained on what it consisted the study and all were willing to participate. ${ }^{8}$ The questionnaire asked on the age, the sex, the clinical manifestations (varies, variceal, edema, ulcer, syndrome 
postrombótico); the symptoms (pain, swelling, restless legs, cramps, ardor, sensation of heavy legs) and some factors of risk characteristic of the illness (sedentarismo, family antecedents of IVC, hormonal treatment, antecedents of deep veined thrombosis, pregnancies, orthopedic defects, bipedestacion, seated position, exhibition to the heat). ${ }^{8}$

Of the total of patients that you/they went to consultation, they were diagnosed the IVC at 57 in the first policlinic and at 44 in the second; for a total of 101 patients. The feminine sex was the most frequent, $84(83,2 \%)$, with a half value for the 66 year-old age, superior to the pickup in the men that it was of 62 years. The total of men of the sample was $17(16,8 \%) .{ }^{8}$ The most frequent clinical manifestations were the variceal and the varies and among the symptoms, the cramps and the heavy legs, The factors of risk with more percentage and that they appeared with same frequency they were the sedentarismo and the orthopedic defects continued by the family antecedents of IVC and the bipedestación. ${ }^{8}$

Sacred Monasteries, it outlines that today's man's sedentary life has influenced notably in the increment of the incidence of veined illnesses, to this he/she is united the habit tabáquico and the inadequate feeding that are at the present time very frequent factors. This has been reaffirmed through recent investigations that have pointed out that the worst enemies in the veined system are the cigarette, the obesity, the inadequate hormonal therapies, the lack of exercises and the reposo. ${ }^{9}$

${ }^{10}$ All these positions are in agreement with the results of this study, where the sedentarismo and the orthopedic defects were the most frequent factors of risk. The illness veined chronicle is frequently view as the primary cardiovascular illness for the magnitude and the impact of the problem, the importance of the veined chronic illness this in the number of patients that you/they suffer, the impact economic partner and the severe of its manifestaciones. ${ }^{10}$

The most serious consequence in the IVC is the veined ulcers they have a dear prevalence of $0,3 \%$, although it is surmised. The presage of it ulcerates her veined it worsens in a general way with the deterioration of the health and the recurrent ulceration. The socioeconomic impact of the veined ulcers is dramatic, being in social and occupational discapacidad. The financial load for veined ulcer in the system of medical attendance is considered in \$1 trillion annually in the treatment of chronic lesions in States Unidos. ${ }^{11}$ The diagnosis and handling of the veined ulcer should begin with the basic understanding of the inferior member's veined system, its components (deep veins, superficial veins and muscles of the inferior extremity), these structures form the one unit physiologic call the bomb of the calf, the damage of anyone of these structures can lead to the reflux veined, typical reference of the inadequacy venosa. ${ }^{12}$ The treatment of IVC from the contention measures and the pharmaceutical treatment, until the boarding surgical. ${ }^{13}$ The appropriate exercises help to maintain inside certain limits the veined inadequacy. To eliminate the hydrostatic pressure on the legs to swim regularly, many times it represents a relief during weeks, in the patient payees of inadequacy venosa. ${ }^{13}$ valuable Therapy that, few patients with IVC can carry out for diverse reasons.

\section{The physical exercise}

The attended active exercises, they are prescribed when the individual is not unable to either carry out the movement, for general weakness or it specifies of one or more muscles, limitations articulares, overweight or other causes that limit it to carry out one or several movements under the influence of the force of graveness. For what you/they need to be aided by the manual work of the fisioterapeuta or for external devices. In England, Olive Guthrie Smith next to Porrit, they designed a series of suspension exercises, by means of springs and pulleys installed in an enclosure type cage and whose technique was denominated, Hidrogimnasia in dry, this technique has been used for the first time by Guthrie Smith in the 1943 as treatment of the sequels of motive affections and being been worth of an assembly in arch form. At the present time it continues being used with the same purpose. ${ }^{14}$ In the program of a patient's exercises, the security is a fundamental consideration in all the aspects and we should have also finds the security of the fisioterapeuta. Particularly when it is manual procedures. The atmosphere in which you/they are carried out the exercises also affects the patient's security. A space of enough dimensions and a surface of appropriate sustentation are requirements indispensables. ${ }^{14}$

In the Hospital Julio Díaz of our capital one carries out a study in patient payees of Multiple Sclerosis, he/she is applied the Cage of Roche with a program of exercises for, to increase the muscular force and to enlarge mobility to articulate, invigoration of hip abduction, adduction, flexion and extension, of lateral cube,flexion and extension of elbows, of supine cube, of cube lateral flexion and knee extension the programs were adjusted in an individual way in dependence of the possibilities evaluated in each individual, increasing the weight progressively. The Cage of Roche endowed with a system of mobile pulleys connected by romanes facilitates to the put to bed patient of supine cube or of lateral cube with the members of having gravitated to carry out pendulous movements with progressive increase of the resistance applying the program of potenciación of Delorme. The load you increases weekly according to valuation of the maximum weight that will be elevated in 10 repetitions $(10 \mathrm{RM}) .{ }^{14}$

\section{Development}

$\mathrm{He} / \mathrm{she}$ makes sure that the most pressing factors of risk that accentuate the symptoms of the IVC are, the habit of smoking, the obesity, the inadequate hormonal therapies, the sedentarismo, and the orthopedic defects . 9,10

The patients with overweight frequently are payees besides orthopedic defects, for what you /they could suffer lesions during the practice of the physical exercise. They are in the services of patient Angiology that, they go to the gym with the firm purpose of, to get rid of some kilos of more. Without having a minimum knowledge of their circulatory problems and the negative repercussion that he/she can have for their health, the indiscriminate practice of exercises that you/they demand a not controlled effort they imply the increase of the abdominal pressure and for it the hydrostatic pressure in the inferior members, worsening the activity of their veined system. Technical considerations and general principles exist for the application and practice of the physical exercise, the space where they are carried out the exercises it will be pleasant, to have enough width and brightness, temperature, appropriate, the patient and the fisioterapeuta will adopt comfortable postures, adapted to each function. The patient must carry out efforts to maintain a certain position. The fisioterapeuta should enjoy the patient's trust along the treatment, helping in great measure to its best cooperation. The mobilizations will be very careful, co- they will begin always with slow movements and they will go increasing their width progressively in function of the looked for objective and of the patient's reaction. During the execution of the 
movements the substitution of incorrect muscular groups should be avoided, the pain should be avoided .Así insofar as possible like the exercise is irreplaceable in the treatment of lesions muscle -articulares, its bad application is not only ineffective but rather in many occasions it is harmful. Before designing a physiotherapy program, it will be necessary to carry out a correct valuation of the muscular functions and articulares, in order to know with accuracy the physiotherapy type that is necesaria. ${ }^{14}$

\section{The personalized physiotherapy}

The physical characteristics of our patients and the immediate of creating alternative of an affordable cost he/she invites us to, to evaluate personalized therapies that they are adjusted our patient payees of the inferior member's illness who with more frequency of the one wanted are people that, they don't classify inside a populational group that he/she enjoys the kindness of the swimming like therapy of maintenance $y / o$ analgesia.

\section{Patient and method}

Analyzing the benefits of finding therapies of feasible costs, to those that can have access an I number bigger than people and to contribute with the prevention of the veined ulcer, more severe manifestation of the IVC. We elaborate a plan of exercises where, the patients with diagnosis of IVC without developing an ulcerous lesion agreed with participating in the study, consistent in a program of exercises in the Cage of Roche to strengthen, muscular groups of the inferior members; the suitable movements were (flexo - knee extension) in position of lateral cube (put to bed on a side with the foot sustained by a leather pulley, carrying out pendulous movements and applying a resistance in contrary address). The variables to measure were, it forces muscular, measurement of the circumference of the calf and the remission of symptoms like, heaviness in the inferior members and pain during the lingering stops.

\section{Material}

Metric tape and cage of roche and test of muscular force.

\section{Results}

The frequency of attendance increased to the treatment from $30 \%$ to $70 \%$. a reduction of $60 \%$ of the recurrence of the relating symptoms was reported in patient payees of IV, sensation of heaviness of the inferior member, constipation (inefficient intestinal evacuation) and the one wanted increase of the muscular force.

\section{Conclusion}

Before the possible increment of the non transmissible illnesses in a world that he/she ages and where the illnesses that require the most expensive therapies, frequently have their biggest impact and incidence, in the poor populations he/she drinks to be our objective, the constant search of alternatives that you/they report benefits of Public Health as the decrease of the lesions and the preservation of the human resources used in the rehabilitation reducing the costs for work accident exploiting to the maximum the spaces and contributing to the saving of the non renewable energy diminishing the costs.

\section{Acknowledgment}

None.

\section{Conflicts of interest}

Author declares that there are no conflicts of interest.

\section{References}

1. OMS. 10 facts about non-communicable diseases. 2011.

2. Arnoldo DC, Linderholm H. On the pathogenesis of of venous leg ulcer. Records Chir Scand. 1968;134(3):427-440.

3. Cabral Als. Inadequacy Veined Chronicle of inferior members: prevalencia, symptoms and markers predictivos [thesis]. Federal University of Sao Paulo: Escola Paulista of Medicine; 2000. P. 231-239.

4. Yamaki T, Hamahata TO, Soejima K, et al. Factors predicting development of post-thrombotic syndrome in patients with to first episode of deep vein thrombosis: preliminary report. Eur J Vasc Endovasc Surg. 2011;41(1):126-133

5. Vasquez MA, Rabe AND, Mc Lafferty RB, et al. Revision of the venous clinical severity score: venous outcomes consensus statement. Special communication of the American Venous Forum. Ad Hoc Outcomes Working Group. J Vasc Surg. 2010;52(5):1387-1396.

6. Lusty F, Jiménez Cossio JA, Ulloa J. The inadequacy veined chronicle in Spain. I study epidemic. Angiología. 2001;53(1):5-16.

7. Guex JJ, Avril L, Enrici AND, et al. Quality of life improvement in Latin American patients suffering from chronic venous disorder using to combination of Ruscusaculeatus and hesperidin methyl-chalcone and ascorbic acid (quality study). Int Angiol. 2010;29(6):525-532.

8. Isabel Cristina Bridges Wood, Alfredo Aldama, Lázaro Chirino Díaz, et al. Ana Alonso Grau. Incidence and prevalencia of the inadequacy veined chronicle in the municipality Hill. Vasc Specialist Int. 2017;33(4):156160 .

9. Hernández Rivero MJ, Llanes Neighborhoods TO, Quiñones Castro M. Characterization of the inadequacy veined chronicle in consultations of the Institute of Angiología and Vascular Surgery. Rev Angiol and Cir Vasc. 2012;11(1):810-815

10. Kahn SR, Ginsberg J. Relationship between deep venous thrombosis and the post-thrombotic Syndrome. Arch Intern Med. 2004;164(1):36-45.

11. Robert T Eberhardt, Joseph D. Raffetto. Inadequacy veined Chronicle. 2015 .

12. Cathy thomas hess. I manage of the ulcer venosa. Nursing. 2004; 22(11):48-49.

13. Jones JE, Nelson. Thin Macías and A. García Miranda. Generalities of the cinesiterapia, Infomed, Specialties, Rev. Cuban of Medicine of Rehabilitation. 2015;12(3):15-28.

14. Origins and Evolution of the Physiotherapy. Ana María Noguera Project educacional University of Salamanca. 2002. 31 p. 